\title{
Documento
}

Document

\section{Uma tradução comentada do artigo de Amedeo Avogadro de 1811, "Tentativa de determinar as massas relativas das moléculas elementares de corpos, e as proporções nas quais eles entram nessas combinações"}

\author{
ADRIANA BISPO DOS SANTOS KISFALUDY \\ Universidade Federal de Mato Grosso do Sul | UFMS \\ WELLINGTON PEREIRA DE QUEIRÓS \\ Universidade Federal de Mato Grosso do Sul | UFMS \\ RICARDO CAPIBERIBE NUNES \\ Universidade Federal de Mato Grosso do Sul | UFMS
}

RESUMO Apresentamos uma tradução comentada do artigo publicado por Amedeo Avogadro em 1811, o qual contribuiu posteriormente para as bases teóricas da determinação do que atualmente é chamado de constante de Avogadro. Em seu artigo Avogadro parte dos estudos de Gay-Lussac sobre os gases que levou a consolidar conceitos que foram utilizados para definir por exemplo molécula. Além disso, o artigo e a tradução do mesmo, permite a compreensão dos conceitos abordados por Avogadro que posteriormente foram desenvolvidos pela química, tais como: determinação de número de mol, cálculos de molaridade, fração molar entre outros.

Palavras-chave Amedeo Avogadro - gases - moléculas 


\section{Introdução}

Amedeo Avogadro (1776-1856) publicou seu artigo “Tentativa de determinar as massas relativas das moléculas elementares de corpos e as proporções nas quais eles entram nessas combinações"1 em 1811, dois anos após Gay-Lussac publicar o artigo "Memórias sobre as combinações de substâncias gasosas umas com as outras" ․․․ Avogadro reafirma as proposições de Gay-Lussac, e, consequentemente, demonstra a teoria apresentada anteriormente sobre as relações gasosas pelo predecessor.

No início de seu artigo, Avogadro faz alusão a Gay-Lussac, citando uma afirmação do mesmo:

... as combinações entre gases se fazem sempre segundo relações muito simples em volume, e que quando o resultado da combinação é gasosa, seu volume também é uma relação simples com aquele que os compõem; mas as relações das quantidades de substancias nas combinações não parecem depender que do número relativo de moléculas que se combinam e das moléculas compostas que resultam. ${ }^{3}$

Nesse contexto, Avogadro começa seu artigo colocando em evidência as afirmações de Gay-Lussac. Isto ocorre, pois Avogadro partiu do trabalho de Gay-Lussac para realizar sua pesquisa. No período histórico, no qual se insere 0 artigo de Avogadro objeto de estudo no presente texto, provavelmente existiam outros pesquisadores que realizavam estudos gasosos, porém os de Gay-Lussac estavam mais próximo do que Avogadro analisava.

Vale ressaltar que um olhar atento a história da ciência permite observar que existia neste período uma troca de informações constante entre os pesquisadores da época. Fato esse comprovado pelas correspondências existentes entre esses pesquisadores. Isso contribuiu muito para o desenvolvimento e compreensão de diversas teorias. Avogadro e Gay-Lussac não ficam longe dessa realidade de troca de informação acadêmica. De fato, observa-se que Avogadro desenvolve um determinado raciocínio, a partir da teoria de Gay-Lussac, quando o mesmo afirma:

A hipótese que se apresenta a esta relação e que pode ser a única admissível, é supor que o número de moléculas integrantes (moléculas) nos gases quaisquer é sempre o mesmo a volumes iguais, ou é sempre proporcional ao volume. $\underline{4}$

Nesse recorte, é possível observar que Avogadro caminha em uma direção que o leva a questionar não somente as características gasosas, mas também, a quantidade de molécula, diferenciando desta forma da teoria apresentada por Gay-Lussac. Essa afirmação pode ser considerada como o princípio de sua proposição teórica. De fato, essa observação se confirma com a seguinte afirmação presente em seu artigo:

Em efeito se supusermos que o número de moléculas contidas em um dado volume fosse diferente para os diferentes gases, não seria possivel de conceber que a lei que irá reger a distância das moléculas pode dar, em todos os casos, que relações simples que os fatos que acabamos de citar nos obrigam a admitir relação entre volumes e moléculas. ${ }^{5}$

Da citação acima, é possível observar o interesse de Avogadro em determinar a relação entre quantidade de moléculas e volume de determinadas espécies gasosas. Para tal, o autor faz todo um levantamento baseado nos estudos de Gay-Lussac, mostrando a relação com a teoria do modelo atômico de Dalton, que apresentava o átomo como se fosse uma bola de bilhar, maciça não divisível. 


\section{Comentários}

Avogadro evidencia no início do artigo o fato de existir uma obscuridade em relação à atração das moléculas, confirmando que poderiam existir leis desconhecidas para a época. Nota-se que o principal objetivo de Avogadro, ao estudar as teorias de Dalton e de Gay-Lussac, era com o propósito de determinar as massas relativas das moléculas formadas, assim Avogadro afirma que:

Partindo dessa hipótese podemos observar um meio de determinar facilmente as massas relativas das moléculas dos corpos no estado gasoso e o número relativo de moléculas em suas combinações, visto que as relações entre massas de moléculas são as mesmas que entre as densidades diferentes dos gases, a pressão e temperatura iguais, e o número relativo de moléculas nessas combinações é dado diretamente pela relação entre os volumes dos gases que o formam. $\underline{G}^{-}$

No fragmento acima, ele faz um paralelo entre os volumes gasosos e a densidade, lembrando que os valores das densidades foram determinados por pesquisadores antecessores a Avogadro, como Berthollet, Kirwam, Davy, e o próprio Gay-Lussac.

No artigo, Avogadro trabalha os cálculos, utilizando-se de proporções para demonstrar as relações entre as diferentes massas dos elementos químicos em um determinado composto, como por exemplo, a relação entre o oxigênio com massa 15,074 para o hidrogênio que é 1, ficaria 15:1. Desta forma, ele apresenta a existência de relação entre as massas dos elementos presentes em um determinado composto.

Na página 19 é abordada a relação presente na molécula da água. Avogadro afirma que a relação de volumes de hidrogênio e oxigênio é de 2:1, sendo a água resultante da união de cada uma dessas espécies. A mesma análise é feita com as proporções estabelecidas por Gay-Lussac, como por exemplo, amoníaco, gás oxigênio e nitroso. Estas relações fornecem a quantidade exata de cada elemento nas substâncias utilizadas no estudo. É importante observar que a grande parte dos cálculos apresentados por Avogadro são básicos, com utilização, principalmente, de regras de três simples, o que demonstra simplicidade de raciocínio para as determinações das massas dos compostos estudados.

Baseado nas análises realizadas, Avogadro, em seu artigo, apresenta uma hipótese sobre os corpos compostos: "parece que uma molécula composta por duas ou mais moléculas elementares ${ }^{\beth}$, devem ter suas massas iguais às somas das massas dessas moléculas". Neste caso, o pesquisador apresenta uma análise relacionando as massas moleculares de determinados compostos com o quantitativo de moléculas presentes na substância, fato esse que nos permite observar o desenvolvimento de definições novas para a compreensão dos conceitos de massa dos compostos químicos e a quantidade de moléculas presentes. Vemos aqui a base teórica para que anos depois seria considerado como fundamento para o que chamamos de constante de Avogadro, no qual coloca em relação à quantidade de moléculas existentes em um determinado composto.

Além disso, Avogadro, em suas análises, apresenta toda a base teórica para os cálculos de mol que é utilizado nos cálculos químicos atuais, o qual ele relaciona a quantidade de moléculas com a massa de gás, o que será utilizado para determinar o que atualmente chamamos de $\mathrm{n}^{0}$ de mol, $\boldsymbol{n}=\frac{\boldsymbol{m}}{\boldsymbol{M M}} \Rightarrow \frac{\text { massa dada }}{\text { massa molecular }}$.

De fato, Avogadro apresenta as concepções teóricas sobre quantidade de moléculas existentes propondo:

É de supor que as moléculas constituintes de um gás simples qualquer, quer dizer o que se mantém a uma distância na qual não pode exercer uma ação mutua, não são formadas de uma só molécula elementar (átomo), mas, resulta de certo número dessas moléculas reunidas em uma só por atração, e que quando moléculas de outras substâncias devem se adicionar a essas para formar outras moléculas compostas, as moléculas que resultam se dividem em duas ou várias partes ou moléculas compostas da metade, de um quarto, etc. da quantidade de moléculas elementares que formaram as moléculas constituintes da primeira substância. ${ }^{9}$ 
Encontra-se, nessa passagem, a explicação do conceito de quantidades de moléculas e substâncias presentes em determinados compostos gasosos, uma vez que toda a análise foi realizada para substâncias gasosas. No entanto, essa afirmação aborda somente os compostos de átomos binários, $\mathrm{H}_{2^{\prime}} \mathrm{O}_{2^{\prime}}$ etc. explicando a questão dos volumes dos produtos.

É evidente no artigo, como afirma Avogadro: "Analisando os diferentes compostos gasosos mais conhecidos, encontro só exemplos em que o volume dobra em relação aos volumes dos componentes." 100 que demonstra que Avogadro procurava relacionar volume com quantidade de moléculas presentes. Esta verificação de Avogadro corrobora com as proposições de Gay-Lussac, ao observar que: "0 volume do gás óxido de nitrogênio é igual a do nitrogênio presente, e consequentemente o dobro do volume do oxigênio". Logo, ambos os pesquisadores tinham a mesma visão teórica do processo de misturas gasosas e seus respectivos volumes.

Na terceira parte do artigo, Avogadro menciona a teoria atômica de Dalton. No entanto, é de fácil observação 0 fato de que Avogadro questiona as proposições de Dalton. Isto é verificado logo no início, quando Avogadro apresenta as propostas de Dalton sobre a quantidade relativa de moléculas nas combinações e diz que Dalton "estabelece relações entre as massas das moléculas dos corpos simples"1ㅡ, apresentando sua hipótese e comparando com as de Dalton, Avogadro afirma:

Nossa hipótese, nos põem em estado, supondo fundamentada, de confirmar ou de retificar esses resultados por dados precisos, e sobretudo, de afirmar que as moléculas compostas segundo os volumes dos compostos gasosos dependem em parte da distribuição das moléculas que este físico não tem nenhuma ideia. $\underline{\underline{12}}$

Essa passagem do artigo demonstra certa rivalidade entre Avogadro e Dalton. Além disso, apresenta conclusões das análises de Avogadro sobre as combinações moleculares dos gases. No entanto, apesar das divergências, Avogadro retoma os cálculos de Dalton e realiza toda uma explicação sobre a molécula de água.

Observa-se que Avogadro verifica os dados de Dalton e os confronta com os resultados de Gay-Lussac, sobretudo no que diz respeito à massa da molécula de água. Além disso, ele utiliza para demonstrar suas conclusões, cálculos simples e valores de densidades determinados por Gay-Lussac e chega à conclusão que:

... o resultado de Dalton é quase justo pela combinação de dois erros que se compõem, o da massa da molécula de oxigênio e de não levar em consideração as combinações. ${ }^{13}$

Logo, Avogadro realiza em seu artigo uma análise minuciosa das afirmações teóricas de Dalton e Gay-Lussac, confrontando-os com suas próprias observações sobre a quantidade de moléculas para os gases estudados. Finalmente, por cálculos diferentes, Avogadro e Gay-Lussac chegaram aproximadamente aos mesmos resultados.

Enfim, as afirmações que Avogadro evidenciou na sua memória, provocou uma discussão durante todo o século XIX, vários pesquisadores não aceitaram as análises elaboradas por Avogadro. Pelo fato de não pertencer a nenhuma comunidade científica da época, não ter um mentor na área, e ainda por ser teórico e não ter seus resultados verificados experimentalmente, seu trabalho não fora reconhecido neste período, sendo somente aceito quase cinquenta anos depois por Stanislao Canizzaro em 1858. ${ }^{14}$

No entanto, a admissão dos estudos de Avogadro sobre gases foi levada em consideração pela comunidade cientifica no começo do século XX, que contribuiu para a determinação da constante de Avogadro, que tem como valor aproximado de 6,022.1023 moléculas, número encontrado facilmente nos livros didáticos atuais e que permitiu o cálculo de várias grandezas químicas. Essa constante sendo muito utilizada na química permite o desenvolvimento de diversos cálculos, como por exemplo: molaridade, número de mols, molalidade, fração molar etc. De modo geral, a constante de Avogadro relaciona a massa atômica com quantidade de moléculas presentes em uma determinada quantidade de substância.

Finalmente, 0 artigo, "Tentativa de determinar as massas relativas das moléculas elementares de corpos, e as proporções nas quais eles entram nessas combinações" desenvolvido por Avogadro contribuiu para uma nova aborda- 
gem dos estudos gasosos e também da compreensão da visão sobre quantidade de átomos, moléculas e partículas existentes em uma determinada quantidade da substância estudada. Esse foi o principal diferencial de Avogadro, visto que ele pôs em evidência essa relação. Consequentemente, essas pesquisas permitiram um avanço significativo no estudo da composição de compostos, assim como, na relação entre os elementos, proporcionando algumas das bases que seriam utilizadas em conceitos estequiométricos. Esse fator permitiu que as análises físico-químicas avançassem no que diz respeito à exatidão dos cálculos.

\title{
Tradução do artigo Essai d'une maniére de determiner les masses relatives des molécules elementaires des corps, et les proportions selon lesquelles elles entrent dans les combinaisons
}

\author{
Tentativa de determinar as massas relativas das moléculas elementares \\ de corpos, e as proporções nas quais eles entram nessas combinações
}

\section{Por A. Avogadro}

0 senhor Gay-lussac mostrou na sua memória interessante (Mémoires de la Societé d'Arcueil, tomo II) que as combinações dos gases se fazem sempre de acordo a relações muito simples em volume, e, que quando o resultado da combinação é gasosa, seu volume e também em relação muito simples com os dos compostos. Mas as relações de quantidades de substâncias nas combinações demonstram não depender do número relativo de moléculas que se combinam, e das moléculas compostas que se resulta. É preciso admitir que existam também relações muito simples entre os volumes das substâncias gasosas e o número de moléculas simples ou compostas que se formam. A primeira hipótese que se apresenta a esse sujeito, e que parece mesmo a única admissivel, é de supor que o número de moléculas integrantes em quaisquer gases é sempre o mesmo a volumes iguais, ou é sempre proporcional aos volumes. De fato, se supomos que o número de moléculas contidas num volume dado é diferente para gases diferentes, não será possível de aceitar que a lei que preside a distância das moléculas, pode dar, em todo caso, relações assim simples que as que viemos de citar, obrigam-nos a admitir entre volume e o número de moléculas. Ao contrário, aceitamos muito bem que as moléculas nos gases estão a uma distância tal que suas respectivas atrações podem se exercer entre si, suas atrações diferentes por calóricos possam se limitar a condensar uma quantidade mais ou menor envolta delas, sem que a atmosfera formada pelo fluido seja mais espaçosa por algumas que por outras, e consequentemente, sem que a distância entre as moléculas verdadeiras, ou, em outros termos, sem que o número de moléculas contidas num dado volume seja ele mesmo diferente. Sr. Dalton, na verdade, propôs uma hipótese diretamente contraria a esse respeito, a saber, que a quantidade de calórico seja sempre a mesma para as moléculas de um corpo qualquer no estado gasoso, e que a tração mais ou menor para o calórico, não faça que condensar mais ou menos esta quantidade de calórico em volta da molécula, e variar assim a distância entre as moléculas; mas na obscuridade onde estamos sobre a matéria, onde está atração de moléculas sobre o calórico é exercida, nada podemos determinar a priori, para uma dessas hipóteses ou pela outra, e somos mais aptos a adotar uma hipótese mista, que fará variar a distância das moléculas e a quantidade de calórico segundo leis desconhecidas se as que viemos propor não forem apoiadas sobre esta simplicidade de relação entre volumes nas combinações dos gases que parece não poder ser explicado de outra forma.

Saindo desta hipótese, vemos que temos o meio de determinar muito tranquilamente as massas relativas das moléculas dos corpos que podemos ter no estado gasoso, e o número relativo dessas moléculas nas combinações; pois as relações de massas das moléculas são, então, as mesmas que as de densidades de diferentes gases, a pressão e temperaturas iguais, e o número relativo de moléculas em uma combinação é dado imediatamente pela relação dos 
volumes de gases que a formam. Por exemplo, os números 1,1035g e 0,07321 exprimem as densidades de dois gases gás oxigênio e gás hidrogênio, quando tomamos o ar atmosférico como unidade, e a relação entre os dois números representam por consequência o número que existe entre as massas de dois volumes iguais desses dois gases, essa mesma relação exprime a hipótese proposta, a relação de massas dessas moléculas. Assim a massa da molécula de oxigênio será aproximadamente 15 vezes a da molécula de hidrogênio, ou mais exatamente, ela será a esta conhecida como 15, 074 a $1 \mathrm{H}_{2}$. Do mesmo modo, a massa de uma molécula de nitrogênio será a do hidrogênio como 0,96913 a 0,07321, quer dizer como 13, ou mais exatamente13,238 à I. De outro lado, como sabemos que a relação dos volumes de hidrogênio ao do oxigênio na formação de água é de 2 para 1, segue-se que a água resulta da união de cada molécula de oxigênio com duas de hidrogênio. Do mesmo segundo as proporções em volumes, estabelecidas pelo Sr. Gay-Lussac nos elementos do amoníaco, dos gases óxidos de nitrogênio, o gás nitroso numa molécula de nitrogênio com uma de oxigênio, e ácido nítrico de uma de nitrogênio com duas de oxigênio.

\section{II.}

Uma reflexão parece inicialmente se opor a admissão de nossa hipótese em relação dos corpos compostos. Parece que uma molécula composta de dois ou mais moléculas elementares devem ter suas massas iguais a soma das massas dessas moléculas, e que particularmente, se na combinação uma molécula de um corpo se junta a uma ou mais moléculas de outro corpo, o número de moléculas compostas deverá continuar a mesma que as das moléculas do primeiro corpo. Segundo esse fato, na nossa hipótese, quando um gás se combina com dois ou mais vezes seu volume de outro gás, o composto que resulta, se ele é gasoso, não poderá ter que um volume igual ao primeiro desses gases. Logo, isso não acontece de forma geral nos fatos. Por exemplo, o volume da água suposta gasosa é, como 0 Sr. Gay-Lussac mostrou, dobra o do gás oxigênio que entre, ou, volta ao mesmo, igual ao do hidrogênio, ao invés de ser igual ao do oxigênio. Mas ele se apresenta naturalmente para explicar os fatos desse gênero conforme a sua hipótese: é possível supor que as moléculas constituintes de um gás simples qualquer, ou seja, as que ficam a uma distância tal a não poder exercer suas ações mútuas, não são formadas de uma só molécula elementar, mas resulta de certo número dessas moléculas reunidas em uma só por atração, e que quando as moléculas de uma substância devem se juntar a essas para formar moléculas compostas, a molécula integrante que deve resultar divide-se em duas ou mais partes ou moléculas integrantes compostas da metade, de um quarto, etc. do número de moléculas elementares que era formada a molécula constituinte da primeira substância, combinada com a metade, com um quarto, etc. do número de moléculas constituintes de outra substância, que devem combinar-se com a molécula total, ou, o que vem a ser 0 mesmo, com um número igual a esta de meia moléculas, de quartos de moléculas, etc. desta substância; de tal forma que o número de moléculas integrantes do composto venha a ser o dobro, quádruplo, etc. do que deveria ser sem 0 compartilhamento, e de tal forma que seja preciso para satisfazer ao volume do gás que resulta.

Procurando os diferentes compostos gasosos mais conhecidos, eu não encontrei exemplos de dobro do volume relativamente ao volume dos seus compostos, que se adiciona uma ou mais vezes seu volume de outro: já vimos para a água. Do mesmo, o volume do gás amoníaco é, como sabemos, o dobro do nitrogênio que é presente. Sr. Gay-Lussac fez ver também que o volume do gás óxido de nitrogênio é igual ao do nitrogênio que faz parte, e consequentemente 0 dobro do oxigênio. Enfim, o gás nitroso que contém volumes iguais de nitrogênio e de oxigênio a um volume igual a soma dos dois gases compostos, ou seja, ao dobro do volume de cada um deles. Assim, em todos os casos deve haver uma divisão das moléculas em duas; mas é possível que em outros casos a divisão se faça em um quarto, em oito, etc. A possibilidade dessa divisão das moléculas poderia ter uma conjunção, mesmo à priori; porque sem essas moléculas integrantes dos corpos compostos de várias substâncias com os números relativos de moléculas, um pouco consideráveis, venham a ser de uma massa excessiva em comparação das moléculas de corpos simples. Podemos, então, pensar que a natureza tem algum meio de fazer entrar nas ordens desses últimos, e, os fatos indicaram-nos a existência desse meio. Aliás, outra consideração parece obrigar-nos a admitir, em alguns casos, a partilha que vem ao caso, pois, como podemos conceber sem ela uma variável combinação entre dois corpos gasosos que se reúnem a volumes iguais, sem que eles sejam condensados, assim que esta tem vez na formação do gás nitroso? As moléculas 
ficam a mesma distância daquelas em que as atrações mútuas das moléculas de cada um dos gases não podem exercer, ou não podem supor que uma nova atração possa acontecer entre as moléculas de um ou as dos outros, mas na hipótese da partilha, vemos bem que a combinação reduz realmente duas moléculas diferentes a uma só, e que haverá contração de todo volume de um dos gases, se cada molécula composta não se dividisse em duas moléculas de mesma natureza. Sr. Gay-Lussac bem viu que segundo os fatos de diminuição de volume nas combinações de gases não podem representar a aproximação de suas moléculas elementares. A partilha das moléculas nas combinações nos explica como essas duas coisas podem ser apresentadas independentes umas das outras.

\section{III.}

0 Sr. Dalton, segundo suposições arbitrárias, que Ihes pareceram as mais naturais em relação ao número relativo de moléculas nas combinações tentou estabelecer relações entre as massas das moléculas dos corpos simples. Nossa hipótese nos coloca num estado, supondo-a fundamentada, de confirmar ou de corrigir seus resultados por dados precisos, e sobretudo, designar o tamanho das moléculas compostas segundo os volumes dos compostos gasosos dependentes em parte da divisão das moléculas que este Físico não tem nenhuma ideia.

Assim Dalton supôs* que a água se forma pela união do hidrogênio e do oxigênio, molécula por molécula. Isto resulta, segundo relações de peso desses dois componentes, que a massa da molécula de oxigênio será a do hidrogênio aproximadamente $7 \frac{1}{2}$ para 1, ou segundo as avaliações de Dalton, como 6 para 1. Segundo a nossa hipótese, esta relação é o dobro, a saber, 15 para 1, como vimos. Quanto à molécula de água, ela deve ter sua massa expressada por $15+2=17$ aproximadamente, tomando por unidade a do hidrogênio, se não existir divisão da molécula em dois, mas por causa dessa divisão ela se reduz de metade ou mais exatamente 8,537, como podemos encontrar imediatamente dividindo a densidade de vapor aquoso 0,625, segundo Sr. Gay-Lussac pela densidade do hidrogênio 0,0732. Essa massa não é diferente de 7, que Dalton tinha designado, que pela diferença nas avaliações da composição da água; de tal forma que a este olhar o resultado de Dalton é mais ou menos justo pela combinação de dois erros que se compensam sobre a massa da molécula de oxigênio e a de não poder ter divisão $8 \frac{1}{2}$.

Dalton supôs que no gás nitroso a combinação de nitrogênio e do oxigênio se faz de molécula a molécula. Vimos que este fato é efetivamente desta forma, segundo nossa hipótese. Assim, Dalton encontrou a mesma massa de moléculas que nós para o nitrogênio, tomando sempre por unidade a do hidrogênio, se ele não tivesse partido de uma avaliação diferente da do oxigênio, e se ele tivesse seguido precisamente a mesma avaliação das quantidades dos elementos do gás nitroso em peso. Mas supondo a molécula de oxigênio menor que a metade da nossa, ele deve ter feito também a do nitrogênio menos da metade da que aviamos designado, a saber, 5 no lugar de 13. Quanto a molécula de gás nitroso mesmo, o defeito da consideração da divisão aproxima-se ainda o resultado de Dalton do nosso; ele fez $6+5=11$, enquanto segundo nós ela é $\frac{15+13}{2}=14$ aproximadamente, ou exatamente $\frac{15,074+13,238}{2}=14,156$ , como encontramos também dividindo 1,03636, densidade do gás nitroso, segundo Gay-Lussac, por 0,07321. Dalton ainda estabeleceu da mesma maneira. Os fatos deram-nos o número o número relativo de moléculas na composição do óxido de nitrogênio e do ácido nítrico, e a mesma circunstância corrigiu o resultado da espessura de uma molécula em relação à primeira; ele fez $6+2.5+16$ enquanto que para nós ela deve ser $\frac{15,074+2.13,238}{2}=20,775$, número que encontramos da mesma forma dividindo 1,52092, densidade do gás óxido de nitrogênio, segundo Gay-Lussac, pelo do gás hidrogênio.

Quanto ao amoníaco, a suposição de Dalton, sobre o número relativo das moléculas na composição, seria inteiramente faltosa segundo nossa hipótese. Ele supôs que o nitrogênio e o hidrogênio unida molécula a molécula, enquanto que vimos que uma molécula de nitrogênio se adiciona três moléculas de hidrogênio. Segundo ele, a molécula de amoníaco seria $5+1=6$; para nós deve ser $\frac{13+5}{2}=8$, ou aproximadamente, 8,119, como isso pode ser deduzido

* $\quad$ No que segue, eu me servirei da exposição de ideias de Dalton; que Thomson nos deu no seu Sistema de Química 
também imediatamente da densidade do gás amoníaco. A divisão da molécula que Dalton não fez entrar no seu cálculo corrige, ainda aqui, em parte o erro resultaria de suas suposições.

Todas as combinações que viemos a percorrer resultam da união de uma molécula de um dos componentes com uma ou várias moléculas da outra. 0 ácido nitroso nos apresenta outra combinação dessas duas substâncias que falamos na qual os dois termos da relação entre o número de moléculas os dois diferentes da unidade. De fato, resulta das experiências de Gay-Lussac a esse sujeito (mesmo volume da Societé d'Arcueil já citado), que este ácido formado de uma parte em volume de oxigênio e três do gás nitroso, ou, o que acaba sendo o mesmo, de três partes de nitrogênio e cinco de oxigênio; de onde ele seguiria, segundo nossa hipótese, que sua molécula, abstração feita de toda a divisão que possa ter, seria composta de 3 moléculas de nitrogênio e 5 de oxigênio. Mas podemos levar desta maneira de composição a forma mais simples dos precedentes, considerando como resultado da união de uma molécula de oxigênio com três de gás nitroso, quer dizer, com três moléculas compostas cada uma de metade da molécula de oxigênio e uma metade de molécula de nitrogênio. 0 que fecha a partilha de algumas moléculas de oxigênio que entra na do ácido nitroso. Supondo outra partilha, a massa desta última molécula será 57,542, a do hidrogênio sendo tomada por unidade, e a densidade do gás ácido nitroso, será de 4,21267, a densidade do ar sendo tomada por unidade, mas é possível que seja feito ao menos uma outra partilha em dois, e por consequência, uma redução da densidade à metade. É preciso esperar que tenhamos determinado esta densidade por experiência.

\section{IV.}

Percorremos ainda algumas outras combinações que possam nos dar, segundo nossa hipótese, conhecimentos ao menos conjunturais sobre as massas relativas das moléculas, e sobre seus números de combinações, e comparemos com a suposição de Dalton.

Sr. Gay-Lussac mostrou que supondo que o ácido sulfúrico seco é composto de 100 de enxofre e 138 de oxigênio em peso, assim que os últimos trabalhos de química estabeleceram, e que a densidade do gás ácido sulfuroso é de 2,265, a do ar sendo tomada por unidade, como Kirwan determinou e admitindo que o ácido sulfúrico seja composto de duas partes de em volume de ácido sulfuroso e uma de gás oxigênio, de forma que resulta das experiências de Gay-Lussac, 0 volume do ácido sulfuroso é aproximadamente o mesmo que do gás oxigênio que entra na relação. Esta igualdade se torna exata se as bases nas quais foram estabelecidas o cálculo fossem elas mesmas. Se supormos a determinação de Kirwan exata, e que rejeitemos o erro sobre a análise do ácido sulfúrico, nós encontraremos no ácido sulfuroso que 100 de enxofre em peso tomam 95,02de oxigênio, e por consequência no ácido sulfúrico 95,02 $\frac{95,02}{2}=142,53$ no lugar de 138. Se, ao contrário, supormos a análise do ácido sulfúrico exato vai seguir que o ácido sulfuroso contém 92 de oxigênio por 100 de enxofre, e seu peso específico deverá ser de 2,30341 no lugar de 2,265.

Uma reflexão parece nos levar a tomar o primeiro partido, até que a densidade do gás sulfuroso seja confirmada ou corrigida por novas experiências; o que deve ter havido na determinação da nova composição do ácido sulfúrico, uma causa de erro tendendo a aumentar a quantidade do radical, ou, o vem ao mesmo, à diminuição do oxigênio. Esta determinação foi feita pela quantidade de ácido sulfúrico seco produzido. Mas parece aproximadamente certo que 0 enxofre ordinário contém do hidrogênio; adicionamos então ao peso verdadeiro do radical, o do hidrogênio que se converteu em água nesta operação. Suponho então o ácido sulfuroso composto de 92,02 de oxigênio para 100 de enxofre, melhor de radical sulfúrico, no lugar de $92^{* *}$.

* Isto foi escrito antes que eu possa ver a Memória do Sr. Davy sobre o ácido oxi-muriático que contem também novas experiências sobre o enxofre e o fósforo. Ele determina a densidade do gás ácido sulfuroso, e encontra que 2,0967, o que dá uma nova força as reflexões que fiz aqui.

Si admitirmos essa densidade, encontramos que no ácido sulfuroso 100 de enxofre utilizam 111 de oxigênio em peso, e no ácido sulfúrico 167 no lugar de 138; mas talvez essa densidade do gás sulfuroso, segundo Davy, peca por defeito. TOME LXXIII, julho de 1811 
Para determinar agora a massa da molécula do radical sulfúrico necessita saber qual é a proporção em volume deste radical suposto gasoso, em relação ao oxigênio na formação do ácido sulfuroso. A analogia tirada de outras combinações que nós falamos, onde existe geralmente o dobro do volume, ou a divisão de uma molécula em dois, leva-nos a supor que o mesmo daquela que se trata, quer dizer, que o volume do gás enxofre é a metade do ácido sulfuroso, e por consequência também do gás oxigênio que entra. Nesta suposição, a densidade do gás de enxofre será a do oxigênio como 100 para $\frac{95,01}{2}$, ou 47,51; o que dá 2,323 para essa metade de gás de enxofre tomando por unidade a do ar. As massas de moléculas sendo, segundo nossa hipótese, na mesma as densidades dos gases que elas pertencem, a massa da molécula do radical sulfúrico será a do hidrogênio como 2,323 à 0,07321, ou como 31,73 à 1. Uma dessas moléculas combinadas, segundo o que tínhamos dito, com dois de oxigênio formara o ácido sulfuroso (abstração feita com relação a divisão), e combinado ainda com uma molécula de oxigênio a mais, formara 0 ácido sulfúrico. Segundo isso, o ácido sulfuroso será análogo, para um número relativo de moléculas desses compostos, ao ácido nítrico, e ácido sulfúrico não haverá de analogia relativamente ao nitrogênio. A molécula do ácido sulfuroso, em relação à divisão será igual à $\frac{31,73+2.15,074}{2}$ ou 30,94, como obtemos imediatamente dividindo a densidade 2,265 do gás ácido sulfuroso, pela do gás hidrogênio. Quanto à do ácido sulfúrico, podemos determinar, por que não sei se tem ainda divisão ulterior, ou não, da molécula na sua formação***.

Dalton tinha suposto que o ácido sulfúrico era composto de duas moléculas de oxigênio sobre um radical, e 0 ácido sulfurosos de uma molécula de oxigênio e de um de enxofre. Essas duas suposições são incompatíveis entre elas, segundo os resultados de Gay-Lussac, os quais as quantidades de oxigênio nesses dois ácidos, por uma quantidade dada de radical, são representadas por 1 e 1/4. Ele partiu para a determinação da molécula, de uma falsa avaliação da composição do ácido sulfúrico, e não foi um acidente que a massa 45, que le pertence, se encontra ter com a massa do oxigênio, segundo ele, uma relação aproximada das massas das duas substâncias apresentam segundo nossa hipótese.

Vejamos agora qual conjuntura nós podemos formar sobre a massa da molécula de uma sustância que joga na natureza um maior papel que o enxofre, ou seja, a do carbono. Como é certo que o volume do ácido carbônico é igual à do gás oxigênio que entra, se admitirmos que o volume do carbono que forma outro elemento, suposto gasoso, dobra-se para dividir as moléculas dos dois, como em diversas combinações desse tipo, é necessário supor que o volume é a metade do gás oxigênio com a qual ele se combina, e por consequência o ácido carbônico resulta da união de uma molécula de carbono e duas de oxigênio, e é também análogo aos ácidos sulfurosos e nítrico $\left(\mathrm{NO}_{2}\right)$ segundo nossas suposições anteriores. Neste caso encontramos, baseado na proporção em peso entre o oxigênio e o carbono, que a densidade do gás carbono seria 0,832 , tomando por unidade a do ar, e a massa da sua molécula 11,3667, tomando por

** Sr. Davy, na Memória citada, fez as mesmas suposições sobre o número relativo das moléculas de oxigênio e do radical no ácido sulfuroso e sulfúrico. Partindo da determinação da densidade do gás ácido sulfuroso, encontramos que a densidade do radical sulfúrico seria de 1,9862, e sua molécula tomando por unidade a do hidrogênio 27,13. Davy por um cálculo análogo fixou a metade aproximadamente, a saber, 13, 7, porque ele supôs segundo a hipótese de Dalton sobre a água, a molécula de oxigênio igual a metade aproximadamente da nossa.

Ele encontrou a mesma massa aproximada, a saber, 13,4 partindo da densidade do gás hidrogênio sulfuroso que é, segundo experiências, 1,0645, resultado um pouco diferente de Kirwan, e supondo que esse gás (que contém, como sabemos, um volume igual ao seu do gás hidrogênio unido ao enxofre) é composto de uma molécula de enxofre e uma de hidrogênio. Como nós supomos a molécula do enxofre tem aproximadamente 0 dobro, nós devemos admitir que o gás resulta da união de uma molécula deste radical com pelo menos dois de hidrogênio, et que seu o volume é o dobro do radical suposto gasoso, como em outros tantos casos, Eu disse: au menos com duas moléculas de hidrogênio, pois já tinha hidrogênio no enxofre ordinário, como as experiências conhecidas desta substância indicam, é necessário adicionar esta quantidade. Se, por exemplo, o enxofre ordinário fosse composto de uma molécula de radical de sulfúrico e de hidrogênio, o hidrogênio sulfúrico será de três moléculas de hidrogênio sobre um radical. Isso poderia se decidir por uma comparação do peso especifico do gás hidrogênio sulfúrico com a do gás ácido sulfuroso, se conhecemos todos os dois exatamente. Por exemplo, supondo exato a do gás hidrogênio sulfúrico. Segundo Davy a molécula do radical sulfúrico nesta suposição de duas moléculas de hidrogênio será somente 27,08, tomando a do hidrogênio pela metade, mas nesta suposição de três moléculas de hidrogênio, 27,08 seria ainda a soma de uma molécula de radical com a do hidrogênio, e a primeira se reduziria consequentemente a 26,08 . Se a densidade do gás ácido sulfuroso exato confirme um ou outro desses resultados, confirmaria deste modo uma e outra dessas hipóteses; mas não somos ainda totalmente de acordo sobre essas densidades para poder tirar alguma conclusão, a este respeito, das determinações que adicionamos até aqui. 
unidade a do hidrogênio. Esta suposição tem no entanto, uma dificuldade contra ela é de dar a molécula de carbono uma massa menor que a do nitrogênio e do oxigênio, enquanto tenderíamos a atribuir a solidez da sua agregação em temperaturas mais elevadas a uma massa mais considerável de moléculas, assim que isto se observa nos radicais sulfúricos e fosfóricos. Chegamos a um resultado que está ao abrigo desta dificuldade supondo na formação do ácido carbônico uma divisão da molécula em quatro ou mesmo oito; pois teríamos desta forma a molécula do carbono dobrado ou quadriplicado desta que vamos estabelecer; mas esta composição não seria análoga a nenhum dos outros ácidos; e por outro lado a forma gasosa ou não, de acordo a outros exemplos que não nos parece depender unicamente do tamanho da molécula, mas também de qualquer outra propriedade desconhecida das substâncias. Assim no vemos 0 ácido sulfurosos sob a forma de gás a pressão e temperatura habitual de atmosfera com uma molécula muito considerável, e aproximadamente igual à do radical sulfúrico que é sólido. 0 gás ácido muriático oxigenado tem uma densidade, e consequentemente uma massa de molécula ainda mais considerável. 0 mercúrio que, como veremos a seguir, deve ter uma molécula extremamente grossa, é, no entanto, gasosa a temperatura infinitamente inferior à que torna tal 0 ferro em sua molécula é menos considerável. Assim nada impede que olhemos o ácido carbônico como composto de maneira indicada acima e por analogia aos ácidos nítrico e sulfuroso, e a molécula do carbono como tendo uma massa determinada por 11,36 .

Dalton fez a mesma suposição que nós sobre a composição do ácido carbônico e foi conduzido por isso a atribuirão carbono uma molécula 4,4 que é a do gás oxigênio, na opinião dele, mais ou menos na mesma relação que 11,36 é a 15, massa a molécula de oxigênio na nossa opinião.

Supondo a massa e a densidade indicada à molécula do carbono e ao gás desta substância, o gás óxido de carbono será formado, baseado nas experiências do Sr. Gay-Lussac que partes iguais em volume de gás de carbono e do gás oxigênio, seu volume será igual a soma dos volumes de seus componentes; consequentemente será formado uma relação do carbono e do oxigênio unidos molécula com molécula com divisão entre os dois; tudo em uma perfeita analogia com o gás nitroso (NO).

A massa da molécula de ácido carbônico será:

$$
\frac{11,36+2 \cdot 15,074}{2}=20,75=\frac{1,5196}{0,07321}
$$

E do gás óxido de carbono será:

$$
\frac{11,36+15,074}{2}=13,22=\frac{0,96782}{0,07321}
$$

\section{V.}

Entre as substâncias simples não metálicas, existe uma que nos falta falar, que, sendo naturalmente gasosa, não pode deixar dúvidas, baseados nos princípios, sobre a massa de sua molécula, mas sobre a qual as últimas experiências do Sr. Davy, e as anteriores ao Sr. Gay-Lussac e Thénard nos forçam a nos distanciar das ideias recebidas até aqui, apesar que esses dois últimos químicos fossem ainda tentar, de explicar segundo suas ideias. Vemos bem que se trata da substância conhecida até aqui sobre o nome de ácido muriático de oxigênio, ou ácido oxi-muriático. Podemos efetivamente, no estado atual de nosso conhecimento olhar esta substância que como ainda sem decomposição, e o ácido muriático que como um composto desta substância do hidrogênio. É então após esta teoria que aplicamos a essas duas substâncias nosso princípio sobre as combinações.

A densidade do ácido óxi-muriático, de acordo com Sr. Gay-Lussac e Thénard é d 2,470, a do ar atmosférico sendo tomada por unidade; isso dá para a molécula, tomando por unidade a do hidrogênio 33,74, partindo da densidade do gás hidrogênio determinado por Sr. Biot e Arago. Segundo Davy 100 polegadas cúbicas inglesa de gás oxi-muriático pesa 74,5 grãos, enquanto que, de acordo com o mesmo, um igual volume de gás hidrogênio pesa 2.27. Isto daria para a molécula 
desta substância $\frac{74,5}{2,27}=32,82$. Essas duas avaliações diferem muito pouco da massa que Sr. Davy determinou para essa substância depois de outras considerações, a saber 32,9. Decorre dessas experiências de Gay-Lussac e Thénard que as de Davy que o gás ácido muriático é formado da combinação de volumes iguais de oxi-muriático e hidrogênio, e que seu volume é igual a sua soma; quer dizer, de acordo com nossa hipótese, que o ácido muriático se forma dessas duas substâncias unidas molécula à molécula com divisão da molécula em duas, como nós já vimos tantos exemplos. Com base nisso, a densidade do gás ácido muriático, partindo do gás oxi- muriático marcado acima, deveria ser 1,272; e é 1,278 a partir das experiências do Sr. Biot e Gay-Lussac. Se supomos esta última determinação exata, a densidade do gás oxi-muriático deverá ser de 2,483, e a massa de sua molécula 33,91. Se queremos adotar de preferência esta avaliação, a massa da molécula do ácido muriático será $\frac{34,91}{2}=17,45=\frac{1,278}{0,07321}$. A determinação do peso específico do gás ácido muriático por Davy, a partir do qual 100 polegadas cúbicas desse gás pesam 39 grãos, daria números um pouco deferentes, a saber 33,36 para a massa da molécula de ácido oxi-muriático e 17,18 para a do ácido muriático.

\section{VI.}

Lendo esta memória, poderemos remarcar, em geral, que existe muitos pontos de acordo entre os resultados particulares e os de Dalton, embora tenhamos partido de um princípio geral e que Dalton não tenha resolvido que sobre considerações particulares. Este acordo depositado em favor de nossa hipótese, que não é no fundo que o sistema de Dalton, munido de um novo meio de precisão pela ligação estabelecida pelo Sr. Gay-Lussac. Este sistema supõe que as combinações se fazem geralmente em proporções fixas, e é este que a experiência faz ver em relação as combinações mais estáveis e mais interessantes para os químicos. São somente eles que podem ter lugar, ao que parece, entre os gases, por causa do tamanho das moléculas que resultaram das relações expressadas pelo maior número de moléculas que é provavelmente formado de estreito limites. Percebemos que a aproximação das moléculas em um corpo sólido e líquido, não deixam mais ainda as moléculas integrantes que das distâncias de mesma ordem que as das moléculas elementares, pode dar lugar a relações mais complicada se mesmo a combinações em todas as proporções; mas essas combinações serão por assim dizer de um outro gênero que as que nos ocupamos, e esta distinção tende a servir para conciliar as ideias do Sr. Berthollet sobre as combinações com a teoria das proporções fixas.

\section{Notas e referências bibliográficas}

Adriana Bispo dos Santos Kisfaludy é pós-graduanda do Programa de Pós-Graduação em Ensino de Ciências do Instituto de Física da UFMS. E-mail: adrianabikis@gmail.com.

Wellington Pereira de Queirós é professor do Instituto de Física da Universidade Federal de Mato Grosso do Sul. E-mail: wellington_fis@yahoo.com.br.

Ricardo Capiberibe Nunes é pós-graduando do Programa de Pós-Graduação em Ensino de Ciências do Instituto de Física da UFMS. E-mail: capiberibe@gmail.com.

1 AVOGADRO, A. Essai d'une manière de determiner les masses relatives des molécules elementaires des corps, et les proportions selon lesquelles elles entrent dans ces combinaisons. Journal de Physique, v. 73, p. 58-76, 1811. Utilizamos a edição que se encontra em ABRAHAM, H.; GAUTIER, H ; LE CHATELIER, H. ; LEMOINE, J. (eds.). Molécules, atomes et notations chimiques. Paris: Librairie Armand Colin, 1913, p. 15-29.

2 GAY-LUSSAC, J.-L. Mémoire sur la combinaison des substaces gazeuses les unes avec les outres. Mémoires de la Societé d'Arcueil, t. II, p. 207, 1809. In: ABRAHAM, H.; GAUTIER, H ; LE CHATELIER, H. ; LEMOINE, J. (eds.). Molécules, atomes et notations chimiques. Paris: Librairie Armand Colin, 1913, p. 1-15.

3 AVOGADRO, op. cit., p. 17.

Idem.

Idem.

Idem, p. 18.

Na visão de Avogadro molécula elementar equivale a átomo.

Avogadro não escreveu essa equação para determinação do número de moles de determinada substância, utilizada em química atualmente, podendo ser encontrada em qualquer livro de química geral. 
10 Idem

11 Idem, p. 21

12 Idem.

13 Idem.

14 BARBAUD, F. (2012). Avogadro, sa constante : entre mythe et réalité. (Éduscol, Editor) Acesso em 24 de setembro de 2018, disponível em Culture Sciences Chimie: http://culturesciences.chimie.ens.fr/content/avogadro-sa-constante\%C2\%A0-entre-mythe-et-r\%C3\%A9alit\%C3\%A9\#Incompr\%C3\%A9hension 